\title{
Antibiotics and Micronutritional Blend to Enhance Fertility Potential in Male Having Abnormal Semen Parameters
}

\author{
Mosammat Rashida Begum ${ }^{*}$, , David Miller ${ }^{2}$, M.A. Salam ${ }^{3}$, Ehsan Quadir ${ }^{4}$, Mosammat Sahina Begum ${ }^{5}$, \\ Farzana Khan $^{5}$ and Zahid Hassan Bhuiyan ${ }^{6}$
}

${ }^{I}$ Dhaka Medical College, Dhaka, Bangladesh

${ }^{2}$ University of Leeds, Leeds $U K$

${ }^{3} B S M M U$, Dhaka, Bangladesh

${ }^{4}$ Sir Salimullah Medical College, Bangladesh

${ }^{5}$ Infertility Care and Research Centre (ICRC), Dhaka, Bangladesh

${ }^{6}$ Bangladesh Medical College, Bangladesh

\begin{abstract}
Objective: Objective of this study was to explore the effect of empirical antibiotics and micro nutritional blends in infertile men having idiopathic oligospermia, asthenospermia and oligoasthenospermia

Materials and Methods: This prospective cross sectional study was undertaken in a tertiary level infertility care unit of Dhaka between September 2005 and December 2007. Two hundred and seven oligo, astheno and oligoasthenospermic patients were the target population for this study. Thorough infertility evaluation was done to identify idiopathic oligo, astheno and oligoasthenospermia. Female partners were also evaluated to exclude bilateral tubal blockage, pelvic inflammatory diseases, endometriosis, uterine pathology and resistant PCOS. Male partners were divided into three groups for I) Antibiotics and micronutrients, II) only micronutrients and III) no intervention as control. Treatment was continued for three months. Semen analysis was repeated at the end of two and three months. Main outcome measures were improvement of semen parameters and pregnancy rate.
\end{abstract}

Results: Before treatment all patients' characteristics were comparable. After treatment there was significant improvement both in count and motility in groups I and II $p<0.05$. In group III where there was no intervention there was no improvement of semen parameters $p>0.05$. Six patients (8.70\%) from group I and 12 patients $(17.29 \%)$ from group II got pregnant within 6 months of observation. No one got pregnant from group III.

Conclusion: Empirical use of antibiotics and micronutrients in idiopathic oligo, astheno and oligoasthenospemia can improve sperm quantity and quality and aid a couple in achieving pregnancy.

Keywords: Micronutrients, oligospermia, asthnospermia.

\section{INTRODUCTION}

There is a growing body of scientific evidence supporting the idea that sperm counts have declined considerably over the last 50 years. The total sperm count as well as sperm quality of the general male population has been deteriorating over the past few decades. This downward trend in sperm count has led to speculation that environmental, dietary or lifestyle changes in recent decades may be interfering with a man's ability to manufacture sperm. About $90 \%$ of male factor infertility is idiopathic with no identifiable cause. Only a minority of affected males has a definite detectable abnormality related to infertility. Associated factors are, endocrine disease 1-3\% [1], antisperm antibodies 3-13\% [2], varicocele $25.4 \%$ [3], genetic cause $10-15 \%$.

*Address correspondence to this author at the $2 / 4$ Block "F", Monjuri, Flat A-1, Lalmatia, Dhaka-1207, Bangladesh; E-mail: rashida_icrc@yahoo.com
Deterioration of semen parameters may be due to exposure (s) to environmental toxicants that alter the reproductive hormones, spermatogenesis or sperm function. The most widely studied evidence of potential environmental reproductive hazards is that sperm counts have declined in certain industrialized countries [4-7]. Various chemicals have been implicated as reproductive toxicants. A number of these chemicals categorized as air pollutants are present in the blood, urine and semen of exposed men and many affect sperm quality. Air pollution may adversely affect semen quality [8-12].

Nutritional and lifestyle changes can improve semen parameters. Reproductive organs are highly susceptible to free radicals or oxidative damage from environmental toxins like pesticides, insecticides and heavy metals. A balanced nutritional diet and nutritional supplements with high antioxidant content can help reverse some of the oxidative damage from environmental toxins and natural aging. Different micronutrients like Vit C, Vit B12, Vit E, 
Arginine, Carnitine, Zinc and Selenium have specific roles in increasing sperm count and improving function [13-16].

Male accessory gland infection (MAGI) is associated with abnormal semen parameters. Both chronic and acute infection of the accessory sex glands result in diminished secretory function. Motility is affected by membrane damage by reactive oxygen species generated by white blood cells. It is estimated that $28 \%$ to $78 \%$ of infertile men have evidence of a chlamydial infection [17]. Chlamydial infection is associated with low sperm count and reduced motility. Sometimes the infection remained completely unrecognized. So the empirical use of antibiotics may sometimes be helpful for unrecognized chlamydial infection.

Considering the positive effects of micronutrients on sperm motility and count a mixture of micronutrients can be applied to reverse sperm parameters. On the basis of published scientific literature on individual nutritional components that benefit fertility, we wanted to use the different components as a blend for oligoasthenospermia. Subclinical epidedymities, which can not be diagnosed by culture, cause oxidative damage of sperm. So empirical antibiotics can also help to maintain sperm function. The purpose of this study is to explore the effect of a micro nutritional blends and empirical antibiotics in infertile men having idiopathic oligospermia, asthenospermia and oligoasthenospermia.

\section{MATERIALS AND METHODS}

This experimental study was conducted in Dhaka Medical College Hospital and Infertility Care and Research Centre (a tertiary level infertility care unit), Dhaka, Bangladesh from September 2005 to December 2007. The study protocol was approved by the institutional review board of Dhaka Medical College, Bangladesh. Informed consent was taken from all patients.

Two hundred and seven infertile male patients who attended the Infertility Care and Research Centre were the target population for this study. Semen analysis was performed on two occasions at 8 week interval and at least one of analysis was at the Infertility Care and Research Centre. Detailed personal history was taken regarding occupation, lifestyle, and personal habit of smoking, alcoholism and drug history. Genital tract infection was evaluated by semen culture and sensitivity and chlamydial antibody testing. Antisperm antibody was tested both in sera and sperm surface. General and endocrinological diseases were identified by clinical examination, hormone analysis, CBC, blood sugar and VRDL testing. Thorough physical examination was done by an andrologist. If any specific cause of oligospermia, asthenospermia or oligoasthenospermia was identified it was excluded from the study. Cases having high FSH level, which indicates compromised testicular function were excluded. Smokers and patients having history of taking any drugs or alcohol were excluded. Fertility assessment of the female partner was done. Uterine pathology, endometriosis, bilateral tubal block, history of pelvic inflammatory diseases, resistant PCOS or any patient who failed to ovulate even with controlled ovarian hyperstimulation were excluded.
All patients were advised to avoid hot environments, diary products, non-organically grown products and to consume organic fruits and vegetables during the study period.

The seminological inclusion criteria were normal appearance, consistency, liquefaction, volume and $\mathrm{pH}$, sperm concentration $<20 \times 10^{6} / \mathrm{ml}$, total motility $<40 \%$, forward motility $<20 \%$ and abnormal sperm $<70 \%$. Selected patients were divided into three groups by lottery.

\section{Group I}

Group I was treated by antibiotics Doxicycline 100mg bd for 1 month followed by micronutrients for 3 months.

Vit C-1 gm daily

Vit E- 800 IU daily

Vit B12-1000 mcg daily

Zinc-120 mg daily

Carnitine-2.64 gm daily

\section{Group II}

Group II was treated with the same micronutrients only for 3 months.

\section{Group III}

Group III were advised about life style changes only; no medication was given, not even placebo as vitamins are usually used for placebo.

All were advised to repeat semen analysis on 2 occasions, at the end of $2^{\text {nd }}$ and $3^{\text {rd }}$ months. Analysis was done by neuber counting chamber. All analyses were done by the same observer. Motility was assessed as percentage of
a) Rapid forward progression
b) Slow forward progression
c) Non progressive
d) Non-motile.

After improvement of semen parameters anovulatory female partners were treated by ovulation inducing agents with monitoring of ovulation. Vit $\mathrm{E}$, Vit $\mathrm{C}$ and Carnitine were continued till pregnancy or for another 6 months to match wife's 6 ovulatory cycles.

Final outcome measures were improvement in sperm count and motility and pregnancy rate.

\section{Data Analysis}

Data were analyzed by SPSS software. Mean \pm SD, students' $t$ test and one way ANOVA were performed for test of significance. A value of $<0.05$ was considered significant

\section{RESULTS}

Two hundred and seven patients were recruited for three management options. Patients were selected on the basis of exclusion of all patients having any specific cause of 
Table 1. Patients' Characteristics

\begin{tabular}{|c|c|c|c|c|}
\hline Age (yr). & $36.22 \pm 2.7$ & $34.96 \pm 3.6$ & $35.13 \pm 3.1$ & 0.342 \\
\hline Duration of Infertility (yrs). & $4.89 \pm 2.7$ & $3.59 \pm 2.1$ & $3.96 \pm 2.4$ & 0.182 \\
\hline \multicolumn{5}{|l|}{ Hormones } \\
\hline $\mathrm{FSH} \mathrm{mU} / \mathrm{ml}$ & $6.46 \pm 1.0$ & $5.70 \pm 1.3$ & $5.72 \pm 1.7$ & 0.112 \\
\hline Prolactin ng/ml & $16.70 \pm 1.6$ & $16.74 \pm 1.1$ & $17.00 \pm 1.2$ & 0.692 \\
\hline Testosterone $\mathrm{ng} / \mathrm{ml}$ & $386.78 \pm 90.3$ & $382.78 \pm 101.4$ & $417.13 \pm 104.0$ & 0.440 \\
\hline Pretreatment Count (mill/ml) & $16.30 \pm 12.25$ & $15.67 \pm 15.15$ & $18 \pm 15.32$ & 0.992 \\
\hline \multicolumn{5}{|l|}{ Pre-Treatment (\%) Motility } \\
\hline Total motility & $33.34 \pm 16.44$ & $39.65 \pm 22.33$ & $38.04 \pm 20.13$ & 0.536 \\
\hline
\end{tabular}

ANOVA.

oligoasthenospermia. All recruited patients were free from any medical diseases.

All three groups had similar characteristics regarding age, duration of infertility, basal hormone levels, pretreatment count and motility (Table 1).

Table 2 shows the pretreatment and post-treatment difference in count and motility. In group I and II (study group) there is a significant difference in count with treatment, $\mathrm{p}<0.001$. There is a $210 \%$ and $108 \%$ increment in group I and group II respectively. But control group (group III), did not show any change in count, $p>0.05$. When it was analyzed in individual group it shows a significant change in motility among treatment groups. In both treatment groups both total and fast forward motility was increased significantly, $\mathrm{p}<0.001$. Total motility increment was $70 \%$ and $52 \%$ and fast forward motility was $50 \%$ and $49 \%$ in group I and II respectively. But in group III there was no change in motility percentage, $\mathrm{p}>0.05$.
Group I was treated by antibiotics and micronutrients and group II were treated by micronutrients only. So postintervention count and motility were compared between the individual groups and Table $\mathbf{3}$ shows that count was increased much more in group I and there is a significant difference between group I and control $p<0.001$. There is also a significant change between group II and control $p<0.05$. Although count was increased in both treatment groups but the increment was significantly higher in group I $\mathrm{p}<0.05$.

Table 3 shows motility compared between treatment and control groups. When group I was compared with control, there was a significant change in total motility $(\mathrm{p}<0.001)$ but not in fast-forward motility $(>0.05)$. On the other hand motility increment was significant in group II in comparison to control for both total $(p<0.001)$ and fast forward $(p<0.05)$. Among the two treatment groups there was no significant difference in motility increment $(\mathrm{p}>0.05)$.

Table 2. Pretreatment and Post Treatment Difference in Count and Motility in Study and Control Group

\begin{tabular}{|c|c|c|c|}
\hline Groups & $\begin{array}{l}\text { Pre Treatment } \\
\text { Mean } \pm \text { SD }\end{array}$ & $\begin{array}{l}\text { Post Treatment } \\
\text { Mean } \pm \text { SD }\end{array}$ & $\begin{array}{c}\text { Significance } \\
\mathbf{p}\end{array}$ \\
\hline \multicolumn{4}{|l|}{ Group I } \\
\hline Count (mill/ml) & $16.30 \pm 12.25$ & $52.54 \pm 25.52$ & 0.000 \\
\hline Total motility (\%) & $33.34 \pm 16.44$ & $56.87 \pm 13.19$ & 0.000 \\
\hline FF motility (\%) & $16.04 \pm 10.34$ & $24.13 \pm 6.33$ & 0.000 \\
\hline \multicolumn{4}{|l|}{ Group II } \\
\hline Count (mill/ml) & $15.67 \pm 15.15$ & $32.63 \pm 21.18$ & 0.000 \\
\hline Total motility (\%) & $39.65 \pm 22.34$ & $60.30 \pm 11.29$ & 0.000 \\
\hline FF motility (\%) & $18.09 \pm 9.87$ & $27.00 \pm 6.13$ & 0.000 \\
\hline \multicolumn{4}{|l|}{ Group III } \\
\hline Count (mill/ml) & $18.00 \pm 15.32$ & $19.41 \pm 16.66$ & 0.486 \\
\hline Total motility (\%) & $38.04 \pm 20.13$ & $33.39 \pm 14.77$ & 0.296 \\
\hline FF motility (\%) & $19.04 \pm 9.30$ & $19.48 \pm 10.08$ & 0.894 \\
\hline
\end{tabular}

Student's t test. 
Table 3. Difference in Post Treatment Count and Motility Between Treatment Group I and Control, Group II and Control and Between Group I and Group II

\begin{tabular}{|l|c|c|c|}
\hline \multicolumn{1}{|c|}{ Count \& Motility } & Group I & Control & Mean \pm SD \\
\hline Count (mill/ml) & $52.54 \pm 25.52$ & $19.41 \pm 16.66$ & 0.000 \\
Total motility (\%) & $56.87 \pm 13.19$ & $33.39 \pm 14.77$ & 0.000 \\
F.F motility (\%) & $24.13 \pm 6.33$ & $19.48 \pm 10.08$ & 0.079 \\
\hline & Group II & Control & Significance \\
\hline \hline Count (mill/ml) & Mean SD & $19.41 \pm 16.66$ & 0.017 \\
Total motility (\%) & $32.63 \pm 21.18$ & $33.39 \pm 14.77$ & 0.000 \\
F.F motility (\%) & $60.30 \pm 11.29$ & $19.48 \pm 10.08$ & 0.014 \\
\hline & $27.00 \pm 6.13$ & Group II & Significance \\
\hline \hline Count (mill/ml) & Group I & Mean \pm SD & 0.006 \\
Total motility (\%) & Mean SD & $32.63 \pm 21.18$ & 0.414 \\
F.F motility (\%) & $52.54 \pm 25.52$ & $60.30 \pm 11.29$ & $27.00 \pm 6.13$ \\
\hline
\end{tabular}

Student's t test.

Table 4 shows the improvement of semen parameters after treatment or after just passage of time. In groups I and II there was $82.61 \%$ and $69.55 \%$ improvement respectively after treatment in terms of count and motility. In group III though there was no intervention, $8.70 \%$ show change of seminal parameters. Six patients $(8.70 \%)$ from group I and 12 patients $(17.29 \%)$ from group II got pregnant within 6 months of observation. No one got pregnant from group III. Though improvement was better in group I, pregnancy rate was higher in group II.

Table 4. Outcome of Treatment

\begin{tabular}{|c|c|c|c|c|c|}
\hline \multirow{2}{*}{ Groups } & \multirow{2}{*}{ Total Patients } & \multicolumn{2}{|c|}{ Improvement } & \multicolumn{2}{|c|}{ Pregnancy } \\
\cline { 3 - 6 } & & $\mathbf{N}$ & $\mathbf{\%}$ & $\mathbf{N}$ & $\mathbf{\%}$ \\
\hline \hline Group I & 69 & 57 & 82.61 & 6 & 8.70 \\
\hline Group II & 69 & 48 & 69.55 & 12 & 17.39 \\
\hline Group III & 69 & 6 & $8.70 \%$ & 0 & 00 \\
\hline
\end{tabular}

\section{DISCUSSION}

Most cases of male infertility are due to an abnormal sperm count or low sperm motility. Low sperm count or motility dramatically reduces the chance of sperm reaching the egg. In about $10 \%$ of the cases of low sperm count the cause can be identified and treated medically.

Nutritional and life style changes increase chances of conception. In known cases fertility potential can be improved by avoiding smoking, caffeine, drugs, alcohol consumption and stress, which are related to infertility. Reproductive organs are highly susceptible to free radicals or oxidative damage from environmental toxicants like pesticides, insecticides, lead, radiation and heavy metals and natural aging. In idiopathic oligospermia and asthenospermia, where there is no specific reason for life style changes, a simple balanced nutritional diet and nutritional supplements with antioxidants can help reverse some of the oxidative damage from environmental toxins and natural aging.

In men certain nutrients are essential for formation of healthy sperm. Micronutrients like vitamin C, vitamin E, L carnitine, zinc, vitamin B complex are critical nutrients in the male reproductive system for proper hormone metabolism, sperm formation and motility. Although high intake of fruits, vegetables, whole grains and nuts are important, supplements are also needed to get sufficient amounts of these nutrients for noticeable effects on sperm quality.

In some cases bacterial infection may cause oxidative damage but infection remains unrecognized even by culture and sensitivity. So empirical antibiotic in some cases may reduce oxidative damage of sperm and improve semen quality. In the present study the two treatment groups showed a marked increment of count and motility of sperm in comparison to the no treatment group. Among twotreatment groups, group I, which included antibiotics showed more improvement than micronutrients alone.

Free radical or oxidative damage to sperm is thought to be responsible for many cases of idiopathic oligospermia. This is causally related to the ability of male germ cells to generate reactive oxygen metabolites. When produced in low levels such metabolites are thought to enhance sperm function by DNA compaction and promoting the induction of sperm capacitation. When produced in excessive amounts, the same metabolites stimulate DNA fragmentation and a loss of sperm function associated with peroxidative damage to the sperm plasma membrane. Use of antioxidants has been shown to be very important in protecting the sperm against damage. Different studies showed the positive effect of 
direct antioxidants in improving sperm count and motility [18-26]. In a double blind placebo controlled study of 110 men with subnormal sperm activity, treatment with 100IU of vitamin $\mathrm{E}$ daily resulted in improved sperm activity [20]. However, a small double blind trial found no benefit from high doses of vitamin E and C [27]. Some studies showed positive effect of using vitamin $E$ in high doses (600 and 800 IU daily) $[28,29]$. In our study we found profound positive effects but we can not isolate the drug effects as we used in combination.

Vitamin $B_{12}$ deficiency in men can lead to reduced sperm counts and lowered sperm motility. For this reason $B_{12}$ supplements have been trialed for improving fertility in men with abnormal sperm production. In one double blind study of 375 infertile men $\mathrm{B}_{12}$ supplementation produced no benefit as a whole [30]. However, weak evidence suggests that $\mathrm{B}_{12}$ supplements may improve sperm count and motility in poor semen parameters [21].

Different double blind placebo controlled trials have demonstrated positive effects of oral L-carnitine and zinc to improve sperm function [22-24, 31-33]. A double blind placebo controlled study showed the significant improvement of sperm count and motility by administration of zinc in infertile men [34]. In the present study zinc and carnitine are also used along with vitamins and the effect of a combination drug is significant.

In the group treated with micronutrients only or by antibiotics plus micronutrients, increase in count and motility is significant in comparison to untreated group (Table 2). As individual micronutrient has positive effect on sperm count and motility this combined effect should be more beneficial. A number of studies have evaluated the benefits of antioxidants for male infertility, which are consistent with the present study also [18-26].

In-group I, $82.61 \%$ of patients showed improvement, which is much higher than improvement shown by group II, $69.55 \%$. Pregnancy rate was lower in group I than in group II despite a greater improvement in count and motility. As pregnancy is the combined result of male and female parameters so improvement of semen parameters is not the sole indicator of a couples' fertility potential.

Microdeletion of the section of the $\mathrm{Y}$ chromosome may be detected in $3 \%$ to $10 \%$ of oligospermic men with normal karyotype $[35,36]$, which can not be detected by karyotyping but can be identified with sequenced -tagged site probes along entire length of the $\mathrm{Y}$ chromosome. Most deletions occur in AZF regions of the long arm of $\mathrm{Y}$ chromosome that contains multiple genes important for spermatogenesis. The limitation of the present study is that we could not do the genetic testing and we may miss chromosomal defects if there is any. Few patients in this study did not respond to treatment at all; genetic problem can not be ignored in those cases.

Treatment of male infertility is a challenge for fertility specialists. Various nutritional strategies have been presented, which have a beneficial impact on sperm count, motility and ultimately fertility. For males with idiopathic infertility, dietary supplementation with a combination of well tolerated, clinically efficacious and non-invasive vitamins and vitamin-like agents (vit $\mathrm{C}, \mathrm{E}, \mathrm{B}_{12}$, carnitine and zinc) provide an alternative pharmacological therapy, which can improve sperm quantity and quality and aid a couple in achieving pregnancy.

\section{REFERENCES}

[1] Vertoppen GR, Steeno OP. Varicocele and the pathogenesis of associated sub-fertility: a review of various theories II: results of surgery. Andrologia 1977; 9: 293.

[2] Bowie W, Pollock HM, Forsyth PS, et al. Bacteriology of the urethra in normal men and in men with nongonococcal urethrities. J Clin Microbiol 1977; 6: 482-8

[3] World Health Organization: The influence of varicocele on paramenters of fertility in a large group of men presenting to infertility clinics. Fertil Steril 1992; 57: 1289.

[4] Carlsen E, Giwercman A, Keiding N, Shakkebaek NE. Evidence for decreasing quality of semen during past 50 years. Br Med J 1992; 305(6854): 609-13.

[5] Moline J, Golden A, Bar-Chama N, et al. Exposure to hazardous substances and male reproductive health: a research framework. Environ Health Perspect 2000; 108: 803-13.

[6] Safe S. Endocrine disrupters and human health. Is there a problem? An update. Environ Health Perspect 2000; 108: 487-93.

[7] Sharpe RM, Skakkebaek NE. Are oestrogens involved in falling sperm counts and disorders of the male reproductive tract? Lancet 1993; 341: 1392-5

[8] Fredricsson B, Moller L, Pousette A, et al. Human sperm motility is affected by plasticizers and diesel particle extracts. Pharmacol Toxicol 1993; 72: 128-33.

[9] Samet JM, Dominici F, Curriero FC, et al. Fine particulate air pollution and mortality in 20 US cities. N Engl J Med 2000; 343 1742-9.

[10] Selevan SG, Borkovec L, Slott VL, et al. Semen quality and reproductive health of young Czech men exposed to seasonal air pollution. Environ Health Perspect 2000; 108: 887-94.

[11] Sram RJ, Binkova B, Rossner P, et al. Adverse reproductive outcomes from exposure to environmental mutagens. Mutat Res 1999; 428: 203-15.

[12] Telisman S, Cvitkovic P, Jurasovic J, et al. Semen quality and reproductive endocrine function in relation to biomarkers of lead, cadmium, zinc, and copper in men. Environ Health Perspect 2001; 108: 45-53.

[13] Goa KL, Brodgen RN. L-carnitine $\neg$ a preliminary review of its pharmacokinetics and its therapeutic use in ischemic cardiac disease and primary and secondary carnitine deficiencies in relationship to its role in fatty acid metabolism. Drugs 1987; 34: 124.

[14] Prasad AS. Zinc in growth and development and spectrum of human zinc deficiency. J Am Coll Nutr 1988; 7: 377-84.

[15] Ursini F, Heim S, Kiess M, et al. Dual function of the selenoprotein PHGPx during sperm maturation. Science 1999; 285: 1393-6.

[16] Hansen JC, Deguchi Y. Selenium and fertility in animals and man a review. Acta Vet Scand 1996; 37: 19-30.

[17] Aitken RJ, Clarkson LS, Hargreave DB, et al. Analysis of the relationship between defective sperm function and the generation of reactive oxygen species in cases of oligospermia. J Androl 1989; 10: 214-20.

[18] Dawson EB, Harris WA, Rankin WE, Charpentier LA, McGanity WJ. Effect of ascorbic acid on male fertility. Ann NY Acad Sci 1987; 498: 312-23.

[19] Moilanen J, Hovatta O, Lindroth L. Vitamin E levels in seminal plasmacan be elevated by oral administration of vitamin $E$ in infertile men. Int J Androl 1993; 16: 165-6.

[20] Suleiman SA, Ali ME, Zaki ZM, et al. Lipid peroxidation and human sperm motility: protective role of vitamin E. J Androl 1996; 17: 530-7.

[21] Sender B, Faragher B. Treatment of oligospermia with vitamin B12. Infertility $1984 ; 7: 133-8$

[22] Loumbakis P, Anezinis P, Russo A, et al. Effect of L-Carnitine in patients with asthenospermia. Eur Urol 1996; 30(suppl 2): 255.

[23] Muller-Tyl E, Lohninger A, Fishchl F, et al. The effect of carnitine on sperm count and sperm motility. Fertilitat [translated from German] 1988; 4: 1-4.

[24] Micic S, Lalic N, Nale DJ, et al. Effects of L-carnitine on sperm motility and number in infertile men. Fertil Steril 1998; 70(3 Suppl 1): $\mathrm{S} 12$. 
[25] Lenzi A, Lombardo F, Agro P, et al. Use of carnitine therapy in selected cases of male factor infertility: a double-blind cross over trial. Fertil Steril 2003; 79: 292-300.

[26] Lenzi A, Sgro P, Salacone P, et al. A placebo-controlled doubleblind randomized trial of the use of combined L-carnitine and Lacetyl-carnitine treatment in men with asthenozoospermia. Fertil Steril 2004; 81: 1578-84.

[27] Rolf C, Cooper TG, Yeung CH, et al. Antioxidant treatment of patients with asthenospermia or moderate oligoasthenospermia with high-dose vitamin $\mathrm{C}$ and vitamin $\mathrm{E}$ : a randomized, placebocontrolled, double-blind study. Hum Reprod 1999; 14: 1028-33.

[28] Kessopoulou E, Powers HJ, Sharma KK, et al. A double-blind randomized placebo cross-over controlled trial using the antioxidant vitamin $\mathrm{E}$ to treat reactive oxygen species associated with male infertility. Fertil Steril 1995; 64: 825-31.

[29] Vezina D, Mauffette F, Roberts KD, et al. Selenium-vitamin E supplementation in infertile men. Effects on semen parameters and micronutrient levels and distribution. Biol Trace Elem Res 1996; 53: 65-83.
[30] Kumamoto $\mathrm{Y}$ et al: Clinical efficacy of mecobalamin in treatment of oligospermia. Results of a bouble blind comparative clinical study. Acta Urol Japan 1988; 34: 1109-32.

[31] Campaniello E, Petrarolo N, Mariggiola MC, et al. Carnitine administration in asthenospermia [abstract] In: IV Int Congress Andrology 1989; May; Firenze. p.14-18.

[32] Vitali G, Parente R, Melotti C. Carnitine supplementation in human idiopathic asthenospermia: clinical results. Drugs Exp Clin Res 1995; 21(4): 157-9.

[33] Costa M, Canale D, Filicori MD, et al. L-carnitine in iriopathic asthenospermia a multicentre study. Andrologia 1994; 26(3): 1559.

[34] Wong WY, Merkus HM, thomas CM, et al. Effects of folic acid and zinc sulfate on male factor subfertility: a double blind, randomized, placebo-controlled trial. Fertil Steril 2002; 77: 491-8.

[35] Pryor JL, Kent-First M, Muallem A, et al. Microdeletions in the Y chromosome of infertile men. N Engl J Med 1997; 336: 534-9.

[36] Kent-First MG, Kol S, Muallem A, et al. The incidence and possible relevance of Y-linked microdeletions in babies born after intracytoplasmic sperm injection and their infertile fathers. Mol Hum Reprod 1996; 2: 943-50.

(C) Begum et al.; Licensee Bentham Open.

This is an open access article licensed under the terms of the Creative Commons Attribution Non-Commercial License (http://creativecommons.org/licenses/by$\mathrm{nc} / 3.0 /$ ) which permits unrestricted, non-commercial use, distribution and reproduction in any medium, provided the work is properly cited. 